\title{
The Relation of Career Adaptability to Values Realization Degree and Organizational Citizenship Behavior
}

\author{
Qingsong Zhu' ${ }^{1}$, Ruiting Tan, Ping Wang \\ Sichuan University, Chengdu, Sichuan
}

\begin{abstract}
The sudden outbreak of the pandemic COVID-19 inevitably has a great impact on economic and social development. Therefore, the innovation-driven value becomes more and more prominent. Through literature review, it is not difficult to find that values have gradually become an important reference standard for organizations to select talents for their teams, as well as an important reference factor for studying organizational citizenship behavior. In order to explore the relationship between values realization degree and organizational citizenship behavior, this investigation based on the social interaction theory was conducting using a sample of enterprise staff $(\mathrm{N}=358)$. In this paper, LISRELV9.2 and SPSS21.0 were used to analyze the sample data, including descriptive statistical analysis, common variance deviation test, reliability and validity test, one-way ANOVA, correlation analysis, regression analysis, and validation of mediating effects. The results showed that values realization degree positively predicted organizational citizenship behavior, and job satisfaction played an intermediary role in the relationship between values realization degree and organizational citizenship behavior. Besides, there were some differences between the relation that work values realization degree and organizational citizenship behavior acted on organizational citizenship behavior.
\end{abstract}

Keywords. Work values realization degree, life values realization degree, job satisfaction, organizational citizenship behavior

\section{Introduction}

With the blurring of organizational boundaries in modern enterprises, the work contents become more challenging. Organizational citizenship behavior was the positive behavior of employees beyond their work roles and was not easily affected by work regulations or work formulations, and could promote organizational performance and innovative behavior [1]. Hence, how to promote organizational citizenship behavior had attracted more and more attention in organizational management.

According to previous literature, values, as the basis for understanding individual attitude cognition and intrinsic motivation, played a leading role in individual behavior. It was an important variable that studying organizational citizenship behavior. The predictive effect of values on organizational citizenship behavior had been widely recognized by researchers [2]. However, the majority of scholars mainly discussed the

${ }^{1}$ Corresponding Author: Ruiting Tan, Sichuan University, Chengdu, Sichuan, China; E-mail: 574409032@qq.com 
influence of values and organizational citizenship behavior from the perspective of individual cognition and behavior, and ignored the role of the environment and emotional attitude. Values were only intrinsic values formed by employees, which could not effectively explain the interaction between employee values and the organizational environment. According to the social interaction theory, human socialization was inseparable from environment, and individual behavior was the product of the interaction between internal cognition and environment. In other words, employees participate in organizational activities and cannot be separated from the organizational environment, it is particularly important to explore the relationship between values and the interactive results of the environment and organizational citizenship behaviors. Besides, in an enterprise, the interaction between employee values and the organization will form value perception or evaluation of the organization. Based on this interactive result, employees tended to form emotional attitudes and made decisions about whether to conduct organizational citizenship behavior.

Therefore, based on the perspective of social interaction theory, this paper introduced the values realization degree as an effective predictor variable and measured the work values and life values realization degree in the organization. In the end, this paper made it easier for managers to track the data of values realization degree to accurately predict employee behavior and made reference to management decisions and enriched the theoretical study of values and behaviors.

\section{Hypothesis and model construction}

\subsection{Values realization degree and organizational citizenship behavior}

Values realization degree refers to the degree which is satisfied or realized in the organizational environment. It is the result of the interaction between individual motivation and organizational environment [3]. Organizational citizenship behavior is an extra role behavior which is not subject to formal regulations and is beneficial to the organization and team [4]. Organizational citizenship behavior has different cultural backgrounds. The spirit of western social psychology lies in individual orientation, while the essence of social psychology in china lies in relationship orientation, and the behavior of employees in china will be affected by the individual relationship background [5]. According to the social interaction theory, the socialization of individual cannot be separated from environment. In organizational context, employee behavior is influenced by the interaction between personal motivation and the organizational environment. If the values of the employees are satisfied well, this interactive result will strengthen the work motivation and attitude of the employees, and further stimulate the employees to make a series of extra-role behaviors. XingChun $\mathrm{Xu}$, a domestic scholar, found that the higher the work values realization degree, the stronger the sense of organizational belonging felt by employees [6]. So they were more likely to take extra-role actions and to repay the satisfaction of the organization to its own work values. 


\subsection{The mediating role of job satisfaction}

Job satisfaction is based on the psychological feeling of the working environment [7]. Smith \& Kendall et al. believed that job satisfaction is an emotional response which is based on the gap between employees' expectations and reality [8]. Scholars agreed that the degree of employees' satisfaction with work depends on the degree of job adaptation. When values realization degree in the organization is high, the needs of employees at the individual level will be well satisfied. Employees were more likely to promoting the positive emotional state of employees. Meanwhile, job satisfaction had a direct predictive effect on employee behavior [9]. The higher job satisfaction was, the easier it was for employees to generate positive emotions and implement behaviors beneficial to the organization, such as high performance and organizational citizenship behaviors [10]. Organ \& Ryan also found that job satisfaction and organizational citizenship behavior were positively correlated. In addition, job satisfaction was closely related to their values orientation [10]. When the organization meets employees' material and spiritual expectations, employees tend to spontaneously reflect high levels of role and out of role behavior performance based on positive emotions [11].

Based on the above analysis, this article made the following hypothesis.

H1a. Life values realization degree positively affect organizational citizenship behavior.

H1b. Work values realization degree positively affect organizational citizenship behavior.

H2a. Life values realization degree positively affect job satisfaction.

$\mathrm{H} 2 \mathrm{~b}$. Work values realization degree positively affect job satisfaction.

H3. Job satisfaction is significantly positively correlated with organizational citizenship behavior.

H4a. Job satisfaction mediates the relationship between work values realization degree and organizational citizenship behavior.

H4b. Job satisfaction mediates the relationship between life values realization degree and organizational citizenship behavior.

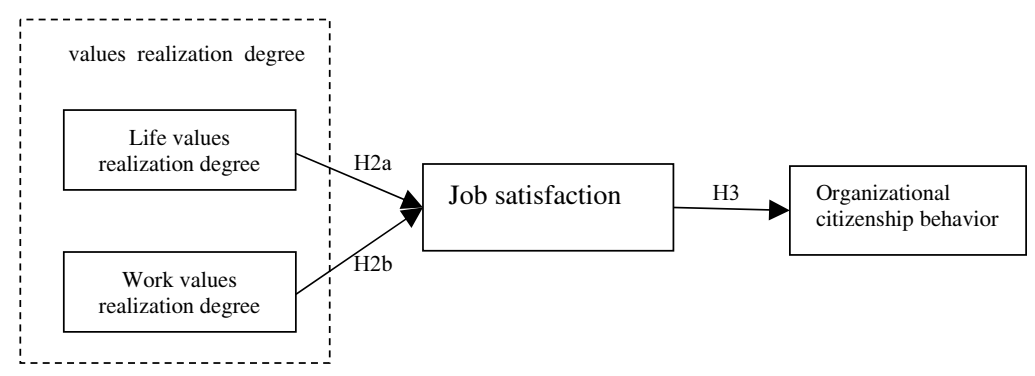

Figure 1. Research framework and model 


\section{Methods}

The study selected 36 enterprises from Beijing, Shanghai, Zhejiang, Sichuan, Chongqing and Hubei to recover questionnaires, covering more than 20 industries, for example, Internet, electronics, finance, water and electricity. Meanwhile, in order to avoid homology error, the work values realization degree questionnaire and the job satisfaction questionnaire were filled out by the employees. But the organizational citizenship behavior was matched by the supervisor. A total of 461 sets of questionnaires were distributed and 385 questionnaires were recovered, with an effective recovery rate of $92.9 \%$. All participants are voluntary and the questionnaires are made anonymous.

\section{Results}

\subsection{Reliability and validity test}

According to confirmatory factor analysis results (Table 1), Values realization degree scale (X2/df) was close to 1, RMR was less than 0.05, GFI, AGFI, CFI, IFI and other indicators were all greater than 0.8 . Therefore, the scale selected in this paper has a good validity. The job satisfaction and organizational citizenship behavior scale (X2/df) is close to 1, RMR is less than 0.05, GFI, AGFI, CFI, IFI and other indicators are greater than 0.7 . Therefore, the scale selected in this paper has a good validity, and its reliability and validity has also been verified to some extent in previous studies of scholars.

Table 1: Results of confirmatory factor analysis

\begin{tabular}{cccccccc}
\hline Index & df & X2/df & GFI & AGFI & CFI & IFI & RMR \\
\hline VRD & 2.45 & 0.81 & 0.79 & 0.89 & 0.87 & 0.89 & 0.04 \\
\hline JS & 3.23 & 0.79 & 0.76 & 0.81 & 0.79 & 0.82 & 0.04 \\
\hline OCB & 3.11 & 0.82 & 0.78 & 0.84 & 0.79 & 0.77 & 0.04 \\
\hline Note: VRD= Values realization degree; JS=Job satisfaction; OCB= organizational citizenship behavior & &
\end{tabular}

Note: $\mathrm{VRD}=$ Values realization degree; JS=Job satisfaction; $\mathrm{OCB}=$ organizational citizenship behavior.

\subsection{Corrlation analysis}

The results of bivariate correlation analysis (Table 2) showed that there was a significant positive correlation between life values realization degree and work values realization degree $(\mathrm{r}=0.537, \mathrm{p}<0.01)$, job satisfaction $(\mathrm{r}=0.294, \mathrm{p}<0.01)$, and organizational citizenship behavior $(\mathrm{r}=0.263, \mathrm{p}<0.01)$. so $\mathrm{H} 1 \mathrm{a}$ was preliminarily verified. There was a significant positive correlation between work value realization and organizational citizenship behavior $(\mathrm{r}=0.262, \mathrm{p}<0.01)$ and job satisfaction $(\mathrm{r}=0.248$, $\mathrm{p}<0.01$ ). so $\mathrm{H} 1 \mathrm{~b}$ was preliminarily verified. Besides, there was a significant positive correlation between employee satisfaction and organizational citizenship behavior $(\mathrm{r}=0.158, \mathrm{p}<0.01)$, and a significant positive correlation between work value realization and organizational citizenship behavior $(\mathrm{r}=0.312, \mathrm{p}<0.01)$. So H3 was preliminarily established. 
Table 2. Correlation analysis

\begin{tabular}{ccccccccc}
\hline & Position & Time & Sex & Age & LVRD & WVRD & OCB & JS \\
\hline Position & 1 & -.052 & $.162^{* *}$ & $-.180^{* *}$ & -.069 & -.063 & .028 & -.049 \\
\hline Time & -.052 & 1 & -.020 & $.399^{* *}$ & -.038 & $-.123^{*}$ & $-.131^{*}$ & -.083 \\
\hline Sex & $.162^{* *}$ & -.020 & 1 & -.017 & $.151^{* *}$ & .037 & $.114^{*}$ & .046 \\
\hline Age & $-.180^{* *}$ & $.399^{* *}$ & -.017 & 1 & -.080 & -.067 & $-.122^{*}$ & .103 \\
\hline LVRD & -.069 & -.038 & $.151^{* *}$ & -.080 & 1 & $.537^{* *}$ & $.263^{* *}$ & $.294^{* *}$ \\
\hline WVRD & -.063 & $-.123^{*}$ & .037 & -.067 & $.537^{* *}$ & 1 & $.262^{* *}$ & $.384^{* *}$ \\
\hline OCB & .028 & $-.131^{*}$ & $.114^{*}$ & $-.122^{*}$ & $.263^{* *}$ & $.262^{* *}$ & 1 & $.158^{* *}$ \\
\hline JS & -.049 & -.083 & .046 & .103 & $.294^{* *}$ & $.384^{* *}$ & $.158^{* *}$ & 1 \\
\hline
\end{tabular}

Note: $* \mathrm{p}<0.05, * * \mathrm{p}<0.01, * * * \mathrm{p}<0.001 ; \mathrm{LVRD}=$ Life values realization degree;

$\mathrm{WVRD}=$ work values realization degree; $\mathrm{OCB}=$ organizational citizenship behaviour; $\mathrm{JS}=\mathrm{J}$ ob satisfaction;

\subsection{Hypothesis test}

According to the results of the regression analysis (Table 3), such as age, these variables had no significant influence on job satisfaction and organizational citizenship behavior. The VIF value of each variable was less than 1.500 , which was far less than the critical value of 10 . Therefore, there was no linear correlation in the equation, which does not affect the test results. In model 2, the regression equation of life value realization degree and job satisfaction is significant $(\mathrm{p}<0.001)$. In terms of regression coefficient $(r=0.297, \mathrm{p}<0.001)$, life values realization degree has a significant positive prediction effect on job satisfaction, so $\mathrm{H} 2 \mathrm{a}$ is verified. In model 3 , the regression variance between the life values realization degree and organizational citizenship behavior was significant $(\mathrm{r}=0.246, \mathrm{p}<0.001)$. so H1a was established. In model 4 , the regression equation of job satisfaction and organizational citizenship behavior was significant $(\mathrm{P}<0.05)$. From the regression coefficient $(\mathrm{r}=0.179, \mathrm{P}<0.001)$, job satisfaction had a significant positive correlation with organizational citizenship behavior of employees. So H3 was established. In model 5, life values realization degree also had a positive prediction effect on the organizational citizenship behavior $(p<0.001)$, but the mediating effect of job satisfaction was not significant $(p>0.05)$. So $\mathrm{H} 4 \mathrm{a}$ was not verified. According to the hypothesis test results (Table 3), the mediating effect of job satisfaction on life values realization degree and organizational citizenship behavior was not significant, and the interval (BootLLCI=-.0052, BootULCI=.0613) contains 0 , that was, hypothesis $\mathrm{H} 4 \mathrm{a}$ was not valid (Table 4). 
Table 3. The regression analysis of life values realization degree, job satisfaction and organization citizenship behavior.

\begin{tabular}{|c|c|c|c|c|c|c|c|}
\hline & \multicolumn{3}{|c|}{ Job satisfaction } & \multicolumn{4}{|c|}{ organizational citizenship behavior } \\
\hline & model1 & model2 & VIF & model3 & model4 & model5 & VIF \\
\hline Position & 0.016 & -0.01 & 1.079 & 0.054 & 0.028 & 0.054 & 1.091 \\
\hline Time & -0.100 & -0.129 & 1.202 & -0.071 & -0.078 & -0.064 & 1.213 \\
\hline Sex & 0.074 & 0.001 & 1.055 & 0.076 & 0.062 & 0.069 & 1.032 \\
\hline Age & -0.066 & 0.17 & 1.25 & -0.062 & -0.088 & -0.074 & 1.271 \\
\hline LVRD & & $0.297 * *$ & 1.038 & $0.246 * *$ & & $0.208 * *$ & 1.145 \\
\hline JS & & & & & $0.179 * *$ & 0.089 & 1.129 \\
\hline $\mathbf{R 2}$ & 0.027 & 0.114 & & 0.085 & 0.058 & 0.091 & \\
\hline $\mathbf{F}$ & 1.869 & 30.633 & & 17.432 & 8.998 & 1.85 & \\
\hline$\Delta \mathbf{R} 2$ & 0.012 & 0.085 & & 0.058 & 0.031 & 0.006 & \\
\hline
\end{tabular}

Table 4. The intermediary test of job satisfaction in life values realization degree and organizational citizenship behavior.

\begin{tabular}{|c|c|c|c|c|c|c|c|}
\hline \multicolumn{8}{|c|}{$\begin{array}{l}\text { OUTCOME VARIABLE } \\
\text { organizational citizenship behavior } \\
\text { Model Summary }\end{array}$} \\
\hline & $\mathrm{R}$ & R-SQ & MSE & $\mathrm{F}$ & DF1 & DF2 & $\mathrm{P}$ \\
\hline \multirow[t]{2}{*}{ Model } & 0.2625 & 0.0689 & 0.2575 & 10.3234 & -0.071 & -0.078 & -0.064 \\
\hline & coeff & se & $\mathrm{t}$ & $\mathrm{P}$ & LLCL & ULCI & \\
\hline Constant & -0.015 & 0.0302 & -0.4973 & 0.6193 & -0.0745 & 0.0445 & \\
\hline \multirow[t]{2}{*}{ Vlues } & 0.1823 & 0.0518 & 3.52 & 0.0005 & 0.0804 & 0.1675 & \\
\hline & & DIRECT A & D INDIREC & FFECTS O & $\mathrm{ONY}$ & & \\
\hline \multicolumn{8}{|c|}{ Direct effct of X on $\mathrm{Y}$} \\
\hline & Effect & $\mathrm{Se}$ & $\mathrm{t}$ & $\mathrm{p}$ & LLCI & ULCI & \\
\hline & 0.1823 & 0.0518 & 3.52 & 0.0005 & 0.0804 & 0.2843 & \\
\hline \multicolumn{8}{|c|}{ Indirect effet (s) of $\mathrm{X}$ on $\mathrm{Y}$} \\
\hline \multirow{2}{*}{$\begin{array}{c}\text { Job } \\
\text { satisfaction }\end{array}$} & Effect & BootSE & BootLLCI & BootULCI & & & \\
\hline & 0.0261 & 0.017 & -0.0052 & 0.0613 & & & \\
\hline
\end{tabular}


According to the test results, after controlling for the variables such as age and these variables, the VIF values of each variable were far less than the critical value of 10. So there was no linear correlation in this equation. In model 2, the regression equation of work values realization degree and job satisfaction was significant $(p<0.01)$. From the regression coefficient $(r=0.297, \mathrm{p}<0.01)$, the work values realization degree had a significant positive prediction effect on employee satisfaction. so H2b was verified. In model 3, the regression equation of work values realization degree and organizational citizenship behavior was significantly positively correlated $(p<0.01)$, and the prediction effect was significant $(r=0.227, p<0.01)$. so H1b was established. In model 4 , job satisfaction had a significant positive correlation with organizational citizenship behavior $(\mathrm{r}=0.179, \mathrm{p}<0.01)$. Therefore $\mathrm{H} 3$ was verified.

In model 4 , job satisfaction was significantly mediated $(\mathrm{p}<0.05)$ between the work values realization degree and organizational citizenship behavior. So H4b was verified.

Table 5. The intermediate inspection of work values realization degree and organizational citizenship behavior

\begin{tabular}{|c|c|c|c|c|c|c|c|}
\hline & \multicolumn{3}{|c|}{ Job satisfaction } & \multicolumn{4}{|c|}{ organizational citizenship behavior } \\
\hline & modell & Model2 & VIF & Model3 & Model4 & Model5 & VIF \\
\hline Position & -0.041 & -0.01 & 1.079 & 0.056 & 0.028 & 0.057 & 1.091 \\
\hline Time & -0.134 & -0.129 & 1.202 & -0.096 & -0.078 & -0.081 & 1.213 \\
\hline $\operatorname{sex}$ & 0.049 & 0.001 & 1.055 & 0.047 & 0.062 & 0.043 & 1.032 \\
\hline age & 0.147 & 0.17 & 1.25 & -0.05 & -0.088 & -0.067 & 1.271 \\
\hline GZJZG & & $0.297 * *$ & 1.038 & $0.227 * *$ & & $0.190 * *$ & 1.145 \\
\hline MYD & & & & & $0.179 * *$ & $0.123 *$ & 1.129 \\
\hline $\mathbf{R 2}$ & 0.029 & 0.114 & & 0.093 & 0.058 & 0.089 & \\
\hline $\mathbf{F}$ & 2.367 & 30.633 & & 20.918 & 8.998 & 3.982 & \\
\hline$\Delta \mathbf{R} 2$ & 0.129 & 0.085 & & 0.060 & 0.031 & 0.013 & \\
\hline
\end{tabular}

Note: ${ }^{*} \mathrm{p}<0.05,{ }^{*} \mathrm{p}<0.01, * * * \mathrm{p}<0.001 ; \mathrm{WVRD}=$ work values realization degree; JS=Job satisfaction;

\section{Discussion}

\subsection{Conclusion and revelation}

The following conclusions are drawn. (1) Values realization degree positively predicts organizational citizenship behavior. (2) Values realization degree positively affects job satisfaction. Employees will form an emotional attitude based on their perception that values are satisfied. (3) Job satisfaction plays an intermediary role in the relationship between values realization degree and organizational citizenship behavior. (4) The life 
values realization degree and the work values realization degree have different influence mechanisms on organizational citizenship behavior. The life values realization degree directly affects organizational citizenship behavior. But the work values realization degree influences organizational citizenship behavior through employee satisfaction.

\subsection{Implications}

First of all, pay attention to the application of employees' values realization degree in management practice. In the selection process, the enterprise presents the relevant information of the organization to the employees reasonably, such as corporate culture, team atmosphere, remuneration, job responsibilities and career development channels. In this way, employees' views and choices on various aspects of the organization are sought to predict the extent to which employees' values are realized in the organizational environment. Then a high reliability and validity assessment tool is established or introduced to achieve the realization of employees' values.

Besides, focus on the role of job satisfaction within the organization and management practices. Enrich the ways and means of obtaining job satisfaction, establish a positive and active two-way feedback mechanism, and break the situation of a single, top-down all-employee survey or satisfaction survey. Secondly, do a good job in analyzing employee satisfaction and reasonable use of job satisfaction of employee behavior.

Finally, exert the influence of organizational environment. By strengthening positive organizational citizenship behaviors, organizations can guide the change of employees' cognition and attitude. For example, talent and organizational development management or organizational values management department seek for employees with high frequency of organizational citizenship behavior to conduct one-to-one interview and communication. The relevant departments conduct personal case publicity in the form of offline lecture forum or online sharing and interaction, create pacesitators of organizational citizenship behavior, and inspire other organizational citizenship behavior.

\subsection{Limitations and future research}

Although the relationship between value realization degree and organizational citizenship behavior is clarified, some research results have been obtained, but the research still has some limitations. Firstly, the research method adopted in this paper is relatively single, which makes it difficult to fully and accurately express the values of the research. Later researcher can adopt more diversified research methods, such as the combination of interview, observation and questionnaire. Besides, the current research on employee values of intergenerational differences is relatively new. In the future, the researcher can consider the influence mechanism of the value realization degree of the post-90s, post-80s and post-70s generation on the behavior of organizational citizens, and explore the difference of the influence of the value realization degree of different age groups on organizational citizens. 


\section{References}

[1] Super DE. A Life-Space Approach to Career Development [J]. Journal of Occupational Psychology, 1980, 16 (3):282-298.

[2] Khckholm C K M. Value and value orientation in the theory of action: an exploratiou in definition and classification, Cambridge: Harvard University Press, 1951.

[3] Qingsong Zhu. An empirical study on the value realization degree matching between employees and organizations and its role [D]. Sichuan University, 2007. Organ D W. Organizational citizenship behavior: The good sol-dier syndrome. Lexington, MA: Lexington Books. 1988.

[4] Xiaolin Zhang, Zhenjiang Qi. Theory of organizational citizenship behavior and its application [J]. Psychology dynamics, 2001, 9 (4): 352-360.

[5] Xingchun Xu. Research on the working values of university teachers and their influence effect [D]. Chongqing: southwest university, 2007.

[6] Hoppock. Job Satisfaction [M].New York: Harper\&Row.1935:236-245.

[7] Smith,Kendall \& Hulin. The measurement of Satisfaction in Work and Retirement: A Strategy for the Study of Attitudes [M]. Chicago: Rand McNally and Company. 1969: 166-188.

[8] Qiwen Qin,Jingzhao Yao,li genqiang. Research on the relationship between work values of enterprise employees and organizational citizenship behavior [J]. Psychological science, 2007, 30 (4): 958-960.

[9] Hofmans J, De Gieter S,Pepermans R. Individual differences in the relationship between satisfaction with job rewards and job satisfaction[J]. Journal of Vocational Behavior, 2013, 82(1):1-9.

[10] Robbins, Stephen P. Organizational Behavior; Concepts, Controversies, and Applications [M]. Prentice Hall (Englewood Cliffs, N,J),1993.

[11] Wiese, B. S.,Freund,A. M.,\& Baltes,P. B. Subjective career success and emotional well-being: Longitudinal predictive power of selection, optimization, and compensation. Journal of Vocational Behavior. 2002, 60, 321-335. 